\title{
Perinatal mortality in Taiwan
}

\author{
PD Wang ${ }^{1 *}$ and RS $\operatorname{Lin}^{2}$ \\ ${ }^{1}$ Public Health Physician and Director, Taipei Wanhwa District Health Center and ${ }^{2}$ Professor and Dean, College of Public \\ Health, National Taiwan University, Taipei, Taiwan
}

\begin{abstract}
Information on perinatal deaths was obtained from 310 women by collecting detailed obstetric histories dating from marriage to the start of the survey. These histories were compared to those of 688 age matched controls. Potential risk factors, levels and time trends of perinatal mortality in Taiwan were examined and factors underlying stillbirths and early neonatal deaths were also compared using conditional logistic regression analyses. A nearly $56 \%$ decline of the perinatal mortality rate during the $35 \mathrm{y}$, approximately, prior to the survey was observed. Risk of stillbirths was increased among those who had abused illegal drugs during pregnancy, those who reported that the pregnancy was unwanted and those with Thalassemia trait. Body mass index was log-linearly related with stillbirths, with higher body mass associated with higher risk. For early neonatal deaths, those mothers aged $19 \mathrm{y}$ or less, those giving birth to either their first children or to their fifth or later child, those who had their first prenatal care visit after the first three months of pregnancy were associated with increased risk in the logistic model. Those with a birth interval of less than two years and those with less education were associated with increased risk in both perinatal death groups. While some of these factors have already been associated with perinatal deaths, others have not; the new associations provide clues to mechanisms by which the risk of death increases before or after delivery.
\end{abstract}

Keywords: perinatal death; body mass index; maternal age; birth interval

\section{Introduction}

Maternal mortality and infant mortality have been widely used for a long time as an index in the evaluation of maternal and child health services. With sharp decreases in the maternal mortality rate (for example the maternal mortality rate has decreased in Taiwan, from 196.6 per 100000 in 1952 to 7.6 per 100000 in 1992), ${ }^{1}$ the perinatal mortality has assumed more importance in the assessment of the health of women and the quality of health care in the perinatal period. Both fetal and neonatal life form a continuum during which human growth and development are affected by genetic and by prenatal conditions and circumstances surrounding delivery. ${ }^{2}$ Many studies have found that the social, economic and cultural influences also affect this continuum. In the United Kingdom, Marmot et $a l^{3}$ found that the infants born to mothers of lower socioeconomic status had about twice the perinatal mortality risk as those born to mothers of upper socioeconomic status. In the United States, Markides et al ${ }^{4}$ found that the significantly higher black perinatal mortality rate over that of white population reflects cultural and socioeconomic factors. Gould et $a l^{5}$ in a cohort study of 127558 women in Los Angeles County, found that the failure of many mothers in the teenage group to use available prenatal care effectively contributes to perinatal mortality. Schieve et $a l^{6}$ in a perinatal registry cohort study of 25746 mothers with ages 20 to $29 y$, found that urinary tract infection was associated with perinatal death. Little et $a l^{7}$ in a study of 3669 married women in the United States, found that smoking cigarettes was associated with increased risk of stillbirths. Bustan et $a l^{8}$ in a longitudinal cohort study of 8823 married, pregnant patients in the United States, found that women who reported that the pregnancy was unwanted were more than twice as likely to deliver infants who died within the neonatal period than

*Correspondence: Dr PD Wang, Director, Wanhwa District Health Center, No 152, Tung-Yuan Street, Taipei, Taiwan.

Accepted 20 August 1996 were women who reported accepting their pregnancies. Despite this, both the rate and distribution of risk factors for perinatal deaths have received relatively less attention in developing countries. Is the same pattern of sociodemographic profile of perinatal deaths duplicated in these countries? In Taiwan, each year there are approximately 320000 live births and more than 6400 deaths during the perinatal period. ${ }^{1}$ However, the cause for the death is frequently unknown, and only a few clear risk factors have been identified. This lack of knowledge may be due in part to the tendency to group all perinatal deaths together regardless of when in the growth process they occur, although deaths that occur during the fetal period may have a different etiology from deaths that occur in the neonatal period.

In addition, most studies of perinatal deaths in developing countries have been characterized by the lack of a properly designed randomized control study, ${ }^{9}$ and to be based on deliveries in a hospital. ${ }^{10}$ The community base of this study reflects the fact that mothers come from a varied background with differing distribution of risk factors and social classes, as distinct from the differential referral rate to hospitals of those with special conditions which can give a misleading picture of the rates of perinatal mortality in a defined community. In order to ascertain whether there are subgroups of the Taiwanese population which are at increased risk of perinatal death and to attempt to provide appropriate preventive measures, we performed a randomized case control study to compare the similarities and differences in the underlying causes of stillbirths (fetal deaths that occur after 22 weeks of gestation) and neonatal deaths (deaths within the first week of birth) to help clarify the role that these underlying causes may play in the perinatal deaths.

\section{Materials and methods}

In the region of the city of Taipei, more than 17000 women attended a family planning service at twelve local health centers from July 1991 to December 1992, all women's 
basic data were stored on tape. Therefore, we were able to check the complete birth history for this population. From the data files of these history records we chose women eligible for our study according to the tenth revision of the International Classification of Disease. ${ }^{11}$ Cases were defined as women reporting perinatal deaths and ascertained through the health center records, including stillbirths (deaths from the 22th week of pregnancy) and neonatal deaths (deaths within the first week of life) during a five year period. A total of 378 eligible subjects were thus identified, restricted to subjects who had no missing values on any of the reproductive variables. Cases were informed by one of the authors (Wang) about the study. Of this group, 49 women $(13 \%)$ declined to take part and 19 women $(5 \%)$ moved from the area, consequently 310 women consented to participate in the study, yielding a response rate of $82 \%$. Because the size of the study was restricted by the number of available cases, we increased the power of the study by including 2 controls per case. For each case two agematched controls. (within $1 \mathrm{y}$ ) were drawn from the local registrar's offices of the community where the cases lived.

Because telephone ownership is widespread in Taipei city, estimated 198.0 per 100 families by Taipei city government during 1994, eligible controls were then contacted by telephone. If the woman consented to participate, she was asked to fill in a questionnaire designed to obtain detailed information about her pregnancy history. All cases and controls were visited by one of sixteen trained public health nurses, within a period of four months, who checked and completed the questionnaire.

A personal and medical questionnaire sought information on maternal demographics, socioeconomic status, cultural and behavioral aspects (including prenatal care payment, family structure and maternal attitude toward pregnancy), reproductive history, prenatal care and other variables. We grouped women into college and over ( $\geq 13 \mathrm{y}$ of education), senior high school (10-12y of education), junior high school (7-9y of education), primary school ( $\leq 6 \mathrm{y}$ of education) and none (illiterate). Maternal attitude towards the pregnancy was grouped on the basis of the woman's response to a question asked during the current pregnancy about her perception of her pregnancy. If the woman stated that she accepted, wanted the pregnancy or she was happy about the pregnancy, the pregnancy was classified as accepted. If the woman indicated that she was unhappy or upset about the pregnancy or did not want the pregnancy, the pregnancy was categorized as unwanted. We examined maternal smoking, drinking and illegal drug abuse during pregnancy and these variables were defined as based on a yes or no answer during pregnancy. Body mass index was computed as weight $(\mathrm{kg}) /$ height $(\mathrm{m})^{2}$. One would expect a difference in factors relating to previous perinatal deaths, compared with those occurring during the study period, and ascertained through the health center records, to minimized the recall bias even in risk factor of body mass index. We excluded variables that were secondary to the outcome of perinatal death (for example, birth weight, weight gain during pregnancy and pregnancy complications) for multivariate analysis.

Conditional logistic regression was carried out for matched series, using the EGRET statistical package. ${ }^{12}$ Stillbirths and early neonatal deaths were examined and all perinatal deaths were also determined regardless of death time. The odds ratio associated with perinatal deaths was estimated by maximum likelihood, this measure of effect can be considered as an estimate of the relative risk. Confidence intervals of $95 \%$ were computed and statistical significance was assessed by two-sided $P$ values at the 5\% level.

\section{Results}

Comparative analyses of characteristics in the case and control population were performed to identify risk

factors for the perinatal death (Table 1 and 2). Univariate analysis for perinatal deaths by timing of death are shown in Table 1. In both perinatal death groups, there was a greater odds ratio of women of less than $20 \mathrm{y}$ of age, women having their first or fifth or higher delivery, women with a birth interval of less than $2 \mathrm{y}$ and women of lower educational level. The contribution of maternal pre-pregnant body mass index to perinatal death risk is evident in the larger odds ratio of mothers in both death groups who have a high body mass index. It is an interesting point to note that prenatal care appeared to have profound benefit. The prenatal care visit data show a trend, the number from 0 to 8 or more visits being positively related to perinatal mortality.

Mothers of perinatal death infants, especially those that died during fetal period, were more likely to report that the pregnancy was unwanted $(\mathrm{OR}=1.5,95 \% \mathrm{CI}=1.1-2.0)$. Differences in mothers with Thalassemia trait $(\mathrm{OR}=2.4$, $95 \% \mathrm{CI}=1.1-5.1)$ and those having illegal drug abuse during pregnancy $(\mathrm{OR}=3.0,95 \% \mathrm{CI}=1.0-10.5)$ were also noted. By contrast, there were associations between neonatal mortality rate and mothers insurance scheme. About $14.6 \%$ of mothers in this study had no health insurance, and from the socioeconomic point of view would be predicted to be socially deprived. Women who reported prenatal care payment by their own money were 2.7 times $(95 \% \mathrm{CI}=1.6-4.6)$ more likely to deliver infants who died within the first $7 \mathrm{~d}$ of life when compared with that among those women who had some insurance, but this factor was not a predictor of stillbirths. The correlation between women reporting that their first prenatal care visit was after the first trimester and early neonatal deaths $(\mathrm{OR}=2.4,95 \%$ $\mathrm{CI}=1.0-7.1) \quad$ was stronger than that of stillbirths $(\mathrm{OR}=0.9,95 \% \quad \mathrm{CI}=0.6-1.3)$. The association with hyperthyrodism and early neonatal deaths is also noted between cases and controls $(\mathrm{OR}=3.6,95 \% \mathrm{CI}=1.1-12.5)$.

After adjusting for all variables, the conditional logistic regression model is shown in Table 2 . For early fetal death, risk was increased among those who had illegal drug abuse during pregnancy $(\mathrm{OR}=3.3,95 \% \mathrm{CI}=1.0-11.3)$, those having an unwanted pregnancy $(\mathrm{OR}=1.8,95 \% \mathrm{CI}=1.1-$ 2.9), and those having the Thalassemia trait $(\mathrm{OR}=3.3,95 \%$ $\mathrm{CI}=1.0-15.3$ ). Body mass index was positively related to stillbirth risk $(\mathrm{OR}=2.5,95 \% \mathrm{CI}=1.3-3.6)$; the estimate effect was remarkably log-linear, the higher the level of body mass index, the higher being the perinatal death rate. Odds ratios for perinatal death are shown in Figure 1 for categories of body mass index. For early neonatal death, maternal age less than $20 \mathrm{y}$ old $(\mathrm{OR}=6.8,95 \% \mathrm{CI}=2.1-$ 30.4), first (OR $=3.3,95 \% \mathrm{CI}=1.5-8.6)$ and over fourth parity $(\mathrm{OR}=2.0,95 \%=1.1-5.4)$, and prenatal care after first trimester $(\mathrm{OR}=2.1,95 \% \mathrm{CI}=1.2-8.7)$, were associated with increased risk of neonatal death. The odds ratio associated with birth interval appears to be similar regardless of the timing of the perinatal death. In addition, absence of education if associated with a raised odds ratio 
Table 1 Univariate analysis for selected variables of fetal death and neonatal death

\begin{tabular}{|c|c|c|c|c|c|c|c|}
\hline \multirow[b]{2}{*}{ Variables } & \multirow[b]{2}{*}{ Controls } & \multicolumn{3}{|c|}{ Fetal period } & \multicolumn{3}{|c|}{ Early neonatal period } \\
\hline & & Deaths & $\begin{array}{l}\text { Odds } \\
\text { ratio }\end{array}$ & $\begin{array}{c}95 \% \\
\text { CI }\end{array}$ & Deaths & $\begin{array}{l}\text { Odds } \\
\text { ratio }\end{array}$ & $\begin{array}{c}95 \% \\
\text { CI }\end{array}$ \\
\hline \multicolumn{8}{|l|}{ Maternal age } \\
\hline$<20$ & 5 & 6 & 3.1 & $1.1-11.9$ & 5 & 7.1 & $2.6-32.4$ \\
\hline $20-29$ & 389 & 149 & 1 & & 55 & 1 & \\
\hline $30-34$ & 241 & 60 & 0.6 & $0.4-1.2$ & 12 & 0.4 & $0.3-1.9$ \\
\hline$>34$ & 51 & 14 & 0.7 & $0.4-1.5$ & 5 & 0.7 & $0.3-2.3$ \\
\hline \multicolumn{8}{|l|}{ Parity } \\
\hline 1 & 90 & 78 & 4.3 & $2.8-6.3$ & 29 & 6.3 & $3.4-11.9$ \\
\hline 2 & 286 & 72 & 1 & & 17 & 1 & \\
\hline 3 & 164 & 44 & 1.3 & $0.8-2.0$ & 23 & 2.8 & $1.4-5.3$ \\
\hline$\geq 4$ & 80 & 37 & 2.3 & $1.4-3.6$ & 9 & 2.2 & $1.0-5.1$ \\
\hline \multicolumn{8}{|l|}{ Birth interval (yr) } \\
\hline$<1$ & 110 & 43 & 2.0 & $1.6-2.8$ & 14 & 2.1 & $1.7-3.2$ \\
\hline $1-2$ & 138 & 42 & 1.5 & $1.2-2.3$ & 12 & 1.4 & $1.0-2.5$ \\
\hline$>2$ & 371 & 74 & 1 & & 23 & 1 & \\
\hline \multicolumn{8}{|l|}{ Residence } \\
\hline Central city & 198 & 71 & 1 & & 20 & 1 & \\
\hline South city & 139 & 48 & 1.0 & $0.5-1.8$ & 22 & 1.8 & $0.9-2.7$ \\
\hline North city & 302 & 99 & 1.0 & $0.7-1.6$ & 35 & 1.3 & $0.4-2.1$ \\
\hline \multicolumn{8}{|l|}{ Work status } \\
\hline Unemployed & 370 & 117 & 1 & & 49 & 1 & \\
\hline Employed & 317 & 114 & 1.1 & $0.8-1.5$ & 30 & 0.7 & $0.4-1.2$ \\
\hline \multicolumn{8}{|l|}{ Household income ${ }^{a}$} \\
\hline$<50000$ & 318 & 105 & 1.0 & $0.5-1.7$ & 41 & 0.9 & $0.4-2.0$ \\
\hline $50000-100000$ & 315 & 107 & 1.0 & $0.6-1.7$ & 30 & 0.7 & $0.3-1.5$ \\
\hline$>100000$ & 55 & 18 & 1 & & 8 & 1 & \\
\hline \multicolumn{8}{|l|}{ Prenatal care payment } \\
\hline Health insurance & 586 & 202 & 1 & & 54 & 1 & \\
\hline Own money & 100 & 29 & 0.8 & $0.5-1.3$ & 25 & 2.7 & $1.6-4.6$ \\
\hline \multicolumn{8}{|l|}{ Educational level } \\
\hline college and over & 148 & 37 & 1 & & 7 & 1 & \\
\hline Senior high school & 302 & 102 & 1.4 & $1.0-1.9$ & 25 & 1.8 & $1.0-2.1$ \\
\hline Junior high school & 119 & 46 & 1.5 & $1.0-2.2$ & 19 & 3.4 & $1.8-5.9$ \\
\hline Primary school & 106 & 39 & 1.5 & $1.0-2.4$ & 23 & 4.6 & $2.0-6.3$ \\
\hline Illiterate & 12 & 7 & 2.3 & $1.0-5.7$ & 5 & 8.8 & $1.2-13.6$ \\
\hline \multicolumn{8}{|l|}{ Ethnic Group } \\
\hline Taiwanese & 504 & 184 & 1 & & 62 & 1 & \\
\hline Hakkaese & 71 & 16 & 0.6 & $0.3-1.1$ & 6 & 0.7 & $0.5-1.7$ \\
\hline Mainlander & 110 & 29 & 0.7 & $0.5-1.1$ & 11 & 0.8 & $0.5-1.9$ \\
\hline Marital status & & & & & & & \\
\hline Single & 6 & 3 & 1.5 & $0.4-6.0$ & 0 & & \\
\hline Currently married & 682 & 228 & 1 & & 79 & & \\
\hline Maternal attitude tow & & & & & & & \\
\hline Accepted & 459 & 133 & 1 & & 48 & 1 & \\
\hline Unwanted & 224 & 98 & 1.5 & $1.1-2.0$ & 31 & 1.3 & $0.8-2.2$ \\
\hline Family structure & & & & & & & \\
\hline Nuclear & 479 & 158 & 1 & & 48 & 1 & \\
\hline Extended & 196 & 68 & 1.1 & $0.8-1.9$ & 29 & 1.5 & $0.8-7.8$ \\
\hline Smoking during pregn & & & & & & & \\
\hline No & 653 & 222 & 1 & & 76 & 1 & \\
\hline Yes & 24 & 7 & 0.9 & $0.6-2.1$ & 1 & 0.4 & $0.2-3.7$ \\
\hline Alcohol use during pr & & & & & & & \\
\hline Never & 492 & 152 & 1 & & 61 & & \\
\hline Sometimes & 167 & 67 & 1.3 & $0.8-1.8$ & 14 & & \\
\hline Everdyay & 5 & 1 & 0.6 & $0.1-3.9$ & 0 & & \\
\hline Illegal drug abuse dur & & & & & & & \\
\hline No & 677 & 225 & 1 & & 77 & 1 & \\
\hline Yes & 5 & 5 & 3.0 & $1.0-10.5$ & 1 & 1.8 & $0.2-15.6$ \\
\hline Birth weight & & & & & & & \\
\hline$\geq 2,500 \mathrm{~g}$ & 657 & 203 & 1 & & 26 & 1 & \\
\hline$<2,500 \mathrm{~g}$ & 30 & 23 & 25.1 & $10.8-34.3$ & 53 & 44.6 & $19.5-59.7$ \\
\hline Body mass index [we & $\left.n)^{2}\right]$ & & & & & & \\
\hline$<19$ & 24 & 5 & 1 & & 2 & 1 & \\
\hline $19-28$ & 613 & 205 & 2.0 & $1.1-2.9$ & 68 & 1.3 & $0.9-3.9$ \\
\hline
\end{tabular}




\begin{tabular}{|c|c|c|c|c|c|c|c|}
\hline$>28$ & 51 & 26 & 2.4 & $1.2-3.4$ & 9 & 2.1 & $1.0-4.1$ \\
\hline \multicolumn{8}{|c|}{ Mother with Thalassemia trait } \\
\hline No & 669 & 213 & 1 & & 72 & 1 & \\
\hline Yes & 16 & 12 & 2.4 & $1.1-5.1$ & 2 & 1.2 & $0.3-5.2$ \\
\hline \multicolumn{8}{|l|}{ Heart disease } \\
\hline No & 674 & 228 & 1 & & 77 & 1 & \\
\hline Yes & 9 & 1 & 0.3 & $0.1-2.6$ & 1 & 1 & $0.1-7.3$ \\
\hline \multicolumn{8}{|l|}{ Hyperthyroidism } \\
\hline No & 675 & 229 & 1 & & 73 & 1 & \\
\hline Yes & 10 & 2 & 0.6 & $0.1-7.5$ & 4 & 3.6 & $1.1-12.5$ \\
\hline \multicolumn{8}{|l|}{ Urinary tract infection } \\
\hline No & 633 & 208 & 1 & & 75 & 1 & \\
\hline Yes & 35 & 9 & 0.8 & $0.4-1.7$ & 2 & 0.5 & $0.1-2.4$ \\
\hline \multicolumn{8}{|l|}{ X-ray exposure } \\
\hline No & 669 & 220 & 1 & & 77 & 1 & \\
\hline Yes & 16 & 8 & 1.5 & $0.6-3.6$ & 2 & 1.1 & $0.3-4.0$ \\
\hline \multicolumn{8}{|c|}{ Time of first prenatal care visits } \\
\hline Within first trimester & 552 & 188 & 1 & & 50 & 1 & \\
\hline After first trimester & 136 & 44 & 0.9 & $0.6-1.3$ & 29 & 2.4 & $1.0-7.1$ \\
\hline \multicolumn{8}{|c|}{ Number of prenatal care visits } \\
\hline 0 & 18 & 18 & 15.4 & $7.1-33.1$ & 12 & 9.2 & $4.0-20.6$ \\
\hline $1-7$ & 286 & 188 & 10.1 & $6.3-17.8$ & 39 & 2.0 & $1.1-3.7$ \\
\hline$\geq 8$ & 384 & 25 & 1 & & 28 & 1 & \\
\hline
\end{tabular}

Note: Because of missing data, numbers available of each variable were often less than the total women interviewed.

a $33.0 \mathrm{NTD}=1.0 \mathrm{USD}$.

Table 2 Conditional logistic regression analysis for perinatal death, fetal death, and neonatal death

\begin{tabular}{|c|c|c|c|c|c|c|}
\hline \multirow[b]{2}{*}{ Variables } & \multicolumn{2}{|c|}{ Perinatal Deaths } & \multicolumn{2}{|c|}{ Fetal Deaths } & \multicolumn{2}{|c|}{ Neonatal Deaths } \\
\hline & $\begin{array}{l}\text { Odds } \\
\text { ratio }\end{array}$ & $\begin{array}{c}95 \% \\
\text { CI }\end{array}$ & $\begin{array}{l}\text { Odds } \\
\text { ratio }\end{array}$ & $\begin{array}{c}95 \% \\
\text { CI }\end{array}$ & $\begin{array}{l}\text { Odds } \\
\text { ratio }\end{array}$ & $\begin{array}{c}95 \% \\
\text { CI }\end{array}$ \\
\hline \multicolumn{7}{|l|}{ Maternal age } \\
\hline$<20$ & 10.9 & $1.8-65.1$ & 5.9 & $0.6-56.5$ & 6.8 & $2.1-30.4$ \\
\hline $20-29$ & 1 & & 1 & & 1 & \\
\hline $30-34$ & 0.6 & $0.3-1.5$ & 0.6 & $0.2-1.7$ & 0.6 & $0.3-4.8$ \\
\hline$>34$ & 0.7 & $0.3-1.7$ & 0.7 & $0.2-2.1$ & 0.7 & $0.3-5.2$ \\
\hline \multicolumn{7}{|l|}{ Parity } \\
\hline 1 & 1.1 & $0.4-2.6$ & 1.4 & $0.4-4.4$ & 3.3 & $1.5-8.6$ \\
\hline 2 & 1 & & 1 & & 1 & \\
\hline 3 & 1.5 & $0.9-2.1$ & 1.2 & $0.6-2.1$ & 1.6 & $0.9-4.8$ \\
\hline $4+$ & 1.7 & $0.9-3.1$ & 1.9 & $0.9-3.8$ & 2.0 & $1.1-5.4$ \\
\hline \multicolumn{7}{|l|}{ Birth interval (y) } \\
\hline$<2$ & 1.6 & $1.1-2.4$ & 1.8 & $1.1-2.8$ & 1.8 & $1.0-5.9$ \\
\hline$\geq 2$ & 1 & & 1 & & 1 & \\
\hline \multicolumn{7}{|l|}{ Educational level } \\
\hline College and over & 1 & & 1 & & 1 & \\
\hline Senior high school & 1.7 & $1.0-4.4$ & 1.6 & $0.9-5.6$ & 1.7 & $1.0-3.5$ \\
\hline Junior high school & 1.9 & $1.1-4.5$ & 2.1 & $1.0-5.9$ & 2.5 & $1.2-7.9$ \\
\hline Primary school & 3.0 & $1.3-6.7$ & 2.6 & $1.1-6.9$ & 3.5 & $1.8-8.4$ \\
\hline Illiterate & 3.1 & $1.3-6.9$ & 4.2 & $1.3-7.6$ & 6.2 & $2.2-11.5$ \\
\hline \multicolumn{7}{|c|}{ Illegal drug abuse during pregnancy } \\
\hline No & 1 & & 1 & & 1 & \\
\hline Yes & 1.8 & $1.0-4.5$ & 3.3 & $1.0-11.3$ & 1.5 & $0.8-15.6$ \\
\hline \multicolumn{7}{|c|}{ Body mass index $\left[\right.$ weight $(\mathrm{kg}) /$ height $\left.(\mathrm{m})^{2}\right]$} \\
\hline$<19$ & 1 & & 1 & & 1 & \\
\hline $19-28$ & 1.7 & $1.1-2.2$ & 2.1 & $2.1-2.8$ & 1.4 & $0.9-5.8$ \\
\hline$>28$ & 2.3 & $1.2-3.0$ & 2.5 & $1.3-3.6$ & 1.8 & $0.9-6.6$ \\
\hline \multicolumn{7}{|c|}{ Maternal attitude toward pregnancy } \\
\hline Accepted & 1 & & 1 & & 1 & \\
\hline Unwanted & 1.8 & $1.1-2.3$ & 1.8 & $1.1-2.9$ & 1 & $0.5-6.9$ \\
\hline \multicolumn{7}{|c|}{ Time of first prenatal care visit } \\
\hline Within first trimester & 1 & & 1 & & 1 & \\
\hline After first trimester & 1.2 & $0.8-1.7$ & 1.2 & $0.7-1.9$ & 2.1 & $1.2-8.7$ \\
\hline \multicolumn{7}{|c|}{ Mother with Thalassemia trait } \\
\hline No & 1 & & 1 & & 1 & \\
\hline Yes & 1.8 & $1.1-13.4$ & 1.5 & $1.0-15.3$ & 1.1 & $0.3-20.8$ \\
\hline
\end{tabular}

Note: Because of missing data, numbers available of each variable were often less than the total women interviewed. 


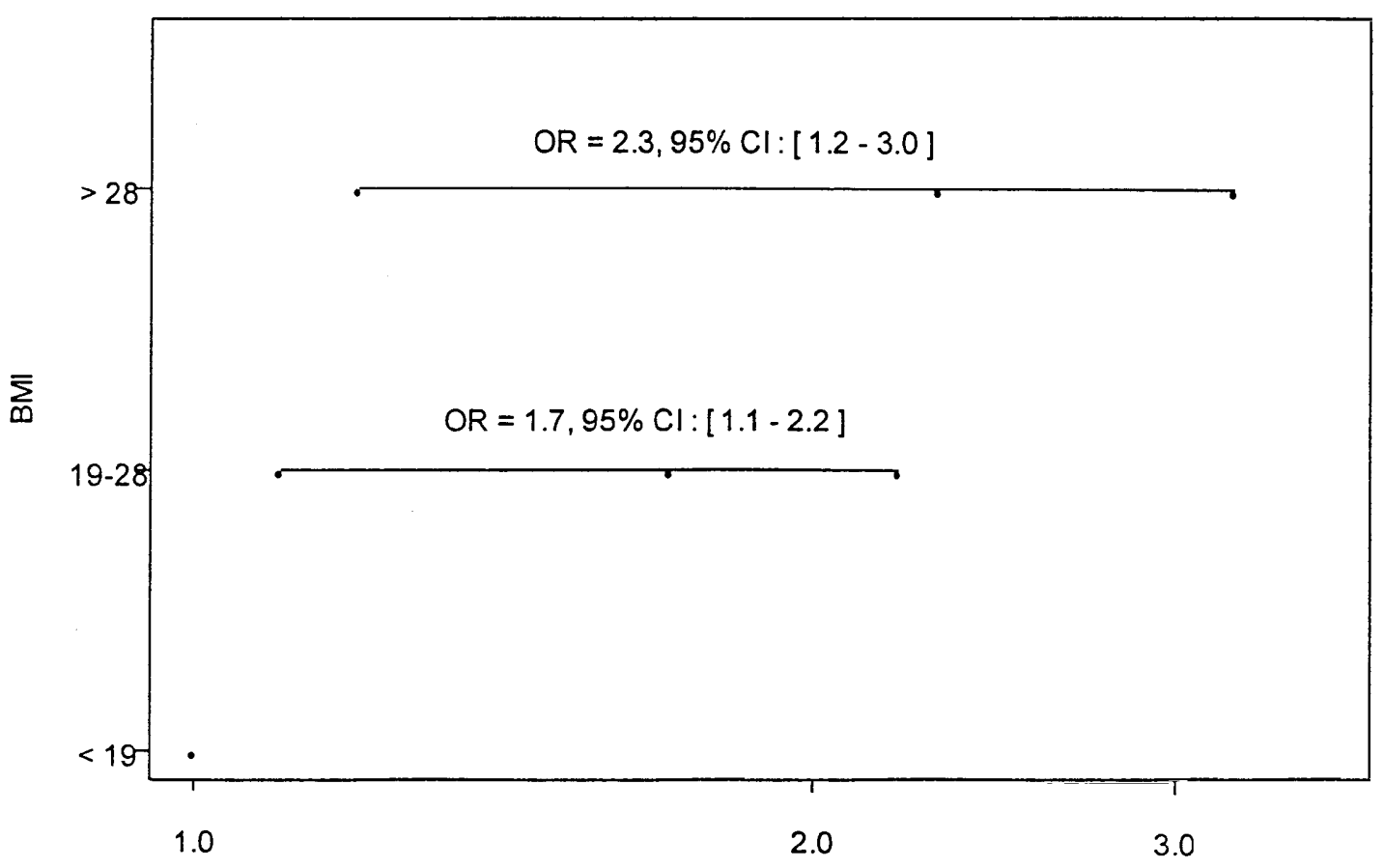

Odds Ratio of Perinatal Death

Figure 1 The odds ratios for perinatal death with $95 \%$ confidence intervals shown, on a log scale, for three categories based on prepregnant body mass index [weight $(\mathrm{kg}) / \mathrm{height}(\mathrm{m})^{2}$. The estimates are based on a model with adjustment for maternal age, parity, birth interval and other important socioeconomic variables.

both for fetal deaths and early neonatal deaths, plus an apparent trend for early neonatal deaths is inversely related to educational level.

Figure 2 is based on reported births and perinatal deaths by the 17044 women who attended the family planning services at twelve local health centers during a five year period. There were 30277 live births, 543 ended in stillbirth, and 186 in neonatal death. Thereby the rate of perinatal deaths by $5 \mathrm{y}$ birth cohorts were estimated and provided a pattern of time trend during the period of about $34 \mathrm{y}$ prior to the surveys. From these results, our country experienced a decline in the perinatal death rate, and the proportionate decline was substantially greater $(65 \%)$.

\section{Discussion}

This was a community-based randomized case-control study. Cases and controls come from the same population, so that the selection bias which may be present when hospital cases are used is avoided. However, a potential source of bias in any case-control study is faulty memory and cases being more likely than controls to recall the details of their past health. These may be major limitations of this study.

According to the Ninth Revision of the International Classification of Disease, perinatal mortality consists of stillbirths and deaths in the first week of life. However, there are international differences in the definition of the perinatal period. For example, in UK and France a minimum gestational age of 24 weeks is applied compared with 16 weeks in Norway. Such differences in definition of a stillbirth may greatly affect the perinatal mortality rate and the issue has been widely discussed since the early 1970s. Addressing this issue, ICD, Ninth Revision recommended that all fetuses and newborn infants with a birth weight of at least $500 \mathrm{~g}$ (the corresponding gestational age of 22 weeks), whether alive or dead, should be included in national perinatal statistics. Therefore we use 22 weeks of pregnancy in the definition.

When all perinatal deaths were considered, regardless of timing of death, several factors were significantly associated with increased risk. Maternal age $19 \mathrm{y}$ or less, birth interval less than $2 \mathrm{y}$, maternal attitude toward unwanted pregnancy, mother with Thalassemia trait, and high body mass index all appeared to increase the risk of perinatal death. Yet, increased education level was protective. A maternal age of $30 \mathrm{y}$ or more also appeared to be protective, although the confidence internal included 1.0. Illegal drug abuse during pregnancy was suggestive of increased perinatal death risk. Though the variable was not a strong predictor, neither can it be considered a good measure of drug use.

Our results showed that the risk of perinatal deaths of babies to mothers under $20 \mathrm{y}$ of age is the highest and gradually decreases to reach a lowest point for mothers 30 $34 \mathrm{y}$ old. Thereafter the risk rises again. This is slightly different with the classical U-shape association with mother's age at birth which presents high rates for mothers aged less than $20 \mathrm{y}$ and over $34 \mathrm{y}$, and a low rate for mothers in between. ${ }^{13}$ However, the U-shaped relationship between age and perinatal mortality had been characterized by the lack of a proper adjusted for parity and social class difference. Younger mothers, having little experience in pregnancy, may be less capable of attending to prenatal care and have a higher prevalence of unwanted or illigitimate births, which may be in part responsible for this rise in the perinatal death for mothers of younger ages. By contrast, the intensive education of older mothers on genetic and prenatal care may thus contribute to the relatively low perinatal mortality rates in Taiwan. 


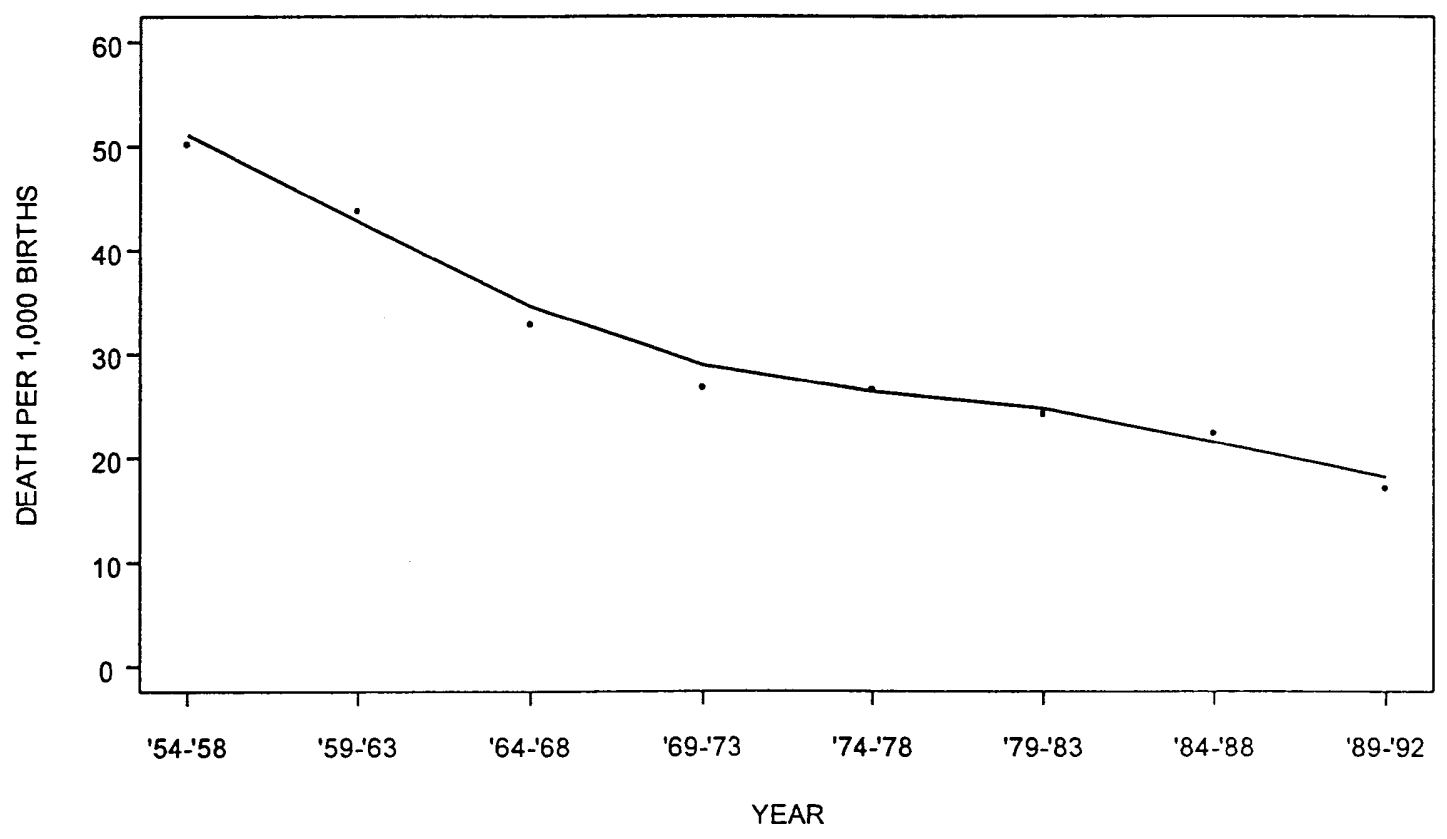

Figure 2 Time trend of perinatal mortality by birth cohort.

First and over fourth parity had a higher risk of early neonatal death than those in second parity. This concurs with the Forbes et $a l^{14}$ study, that revealed the J-shaped relation of parity with neonatal death, while the risk increase by 1.8 times for those with a birth interval of less than $2 \mathrm{y}$. This finding supports Hobcraft's study of short interval between birth associated with a higher risk of mortality. In the case of birth interval, 'maternal depletion syndrome' 1516 is often cited as a mechanism causing deleterious effect which could lead to perinatal deaths. A mother with reported pregnancies, especially at short intervals, does not have sufficient time for recovery, both physically and nutritionally, and is more likely to have pregnancy losses.

Educational level is thought to be the most reliable indicator of socioeconomic status for countries like Taiwan, where the subject of household income is very private and the women are embarrassed to discuss this during the interview. It can be seen that there were significant differences in perinatal mortality according to the maternal education variable. The educational level of the mother showed a linear trend, with the highest perinatal mortality rates among the relatively illiterate mothers, and the lowest mortality rates among mothers who had completed college.

The relation of these factors to the risk of stillbirth is different from that for early neonatal deaths, and was one of the variables that differentiated the perinatal death groups most strongly. For stillbirths, illegal drug abuse during pregnancy had an odds ratio significantly larger than 3.0. Mothers with the Thalassemia trait or unwanted pregnancy also had an apparent relation to increased stillbirth risk. A possible relation of maternal attitude toward unwanted pregnancy and stillbirth is supported by Bustan's study ${ }^{8}$ in a longitudinal cohort study of 8823 married, pregnant women. In addition, we know of no prior study of the association of Thalassemia and perinatal death risk. An estimate of the prevalence of Thalassemia trait in the Taiwanese population is about $1.5 \%$ for $\alpha$-Thalassemia and
$3.5 \%$ for $\beta$-Thalassemia. Younger mothers and those having first and over fourth parity, on the other hand, showed a larger odds ratio for early neonatal deaths than for stillbirths.

In 1988, Cnattingius, et $a l^{17}$ observed a dose-response relation between smoking and stillbirth risk. But Schwartz et $a l^{18}$ in a prospective study of 6989 women, did not observe such a relation. Some information on smoking habits was collected in our study; however, the prevalence of smoking is very low among females in Taiwan (An estimate of smoking level is around $4.5 \%$ ), and did not differ between cases ( 7 out of 229) and controls (24 out of 677).

Kaminski et al ${ }^{19}$ reported heavy drinking during pregnancy to increase the risk of stillbirth by more than twice. Little et $a l^{20}$ reported that alcohol dose and reproductive risk for birth weight and preterm delivery is in a J-curve relation. However, the present study provided little power to detect such an association, if it existed, since few women in the sample reported heavy drinking.

Pre-pregnant body mass index was a strong predictor of risk of perinatal death. The significantly stronger effect of this variable in stillbirths suggests that the mechanisms by which it increases risk may be different in the timing of death. Naege ${ }^{21}$ reported that women in the highest category of weight for height were found to have significantly elevated stillbirth risk. This increase in the mortality rate was partially due to the complications of materal hypertension, oedema or diabetes mellitus. However, obesity seems to have a genetic component, and for some women it may be one symptom or sign of a complex of health problems that can include reproductive dysfunction. After labour starts, the mechanical problems of delivering the baby of an obese woman could be very important. ${ }^{7}$

Several variables commonly used in reproductive analyses have not been included here. Birth weight, gestational age and weight gain during pregnancy may all be reduced if fetal death has interrupted the pregnancy, and 
thus have not been included in the model as a variable, although the association with gestational age etc. is an important contributory factor to perinatal death.

In the last $35 \mathrm{y}$, neonatal deaths in Taiwan have declined by nearly $90 \%$; the neonatal mortality rate dropped from 18.9 per 1000 live births in 1956 to 1.8 in 1992 . However, has the decline kept pace with the decline in fetal death rate? Unfortunately, since fetal death data is not routinely recorded in Taiwan, the mortality rate of stillbirths are not available either as routinely published data or from specialized researches.

Up to the present time, most interventions designed to reduce mortality in the perinatal period focused on medical interventions (for example the neonatal intensive care strategy of Taiwan). Nevertheless, we have provided a method to combine social and medical sciences study to identify the risk factors of perinatal death, such as in younger mothers, illegal drug abuse, maternal attitude toward unwanted pregnancy, mother with Thalassemia trait and body mass index. This method could help to elucidate the mechanism by which risk is increased and may suggest useful preventive interventions in high risk groups.

\section{Acknowledgements}

This research was supported under No. DOH83-HP-22 from the Department of Health, Executive Yuan. The authors wish to express their gratitude to the sixteen public health nurses for their home visits interview. Thanks are also due to Professor Yuh Y. Pan for her helpful comments.

\section{References}

1 Department of Health, the Executive Yuan. Health and Vital Statistics in the Taiwan Area 1952-1992. Department of Health, Executive Yuan: Taipei, 1993.

2 Behrman RE, Kliegman RM, Nelson WE, Vaughau VE. Nelson's Textbook of Pediatrics, 14th Edn. W.B. Saunders Company: Philadelphia, Pennsylvania, 1992, pp 421-422.

3 Marmot MG, Morris JN. The social environment. In: Oxford Textbook of Public Health, Vol.1, Hollant WW, Detels R, Knox G (eds). Oxford University Press: Oxford:, 1984, pp 97-118.

4 Markides KS. Mortality among minority populations: a review of recent patterns and trends. Public Health Reports 1983; 98: $252-260$.
5 Gould JB, LeRoy S. Socioeconomic status and low birth weight: A racial comparison. Pediatrics 1988; 82: 896-904.

6 Schieve LA et al. Urinary tract infection during pregnancy: Its association with maternal morbidity and perinatal outcome. Am J Public Health 1994; 84: 405-410.

7 Little RE, Weinberg CR. Risk factors for antepartum and intrapartum stillbirth. Am J Epidemiol 1993; 173: 11771189.

8 Bustan MN, Coker AL. Maternal attitude toward pregnancy and the risk of neonatal death. Am J Public Health 1994; 84: 411-414.

9 Chryssa TB, Vasso LK, Matsaniotis NS, Golding J. The Greek national perinatal survey. II: Socioeconomic factors and perinatal mortality in Greece. Paediatr Perinat Epidemiol 1989; 3: 41-52.

10 Milaat WA, Du V Florey C. Perinatal mortality in Jeddah, Saudia Arabia. Int J Epidemiol 1992; 21: 82-90.

11 World Health Organization. ICD-10. International Statistical Classification of Diseases and Related Health Problems. Tenth Revision. Vol. 2, Instruction Manual. World Health Organization: Geneva, 1993, pp 130-132.

12 Statistics and Epidemiology Research Corporation. EGRET User's Manual, (copyright) 1985-1988. Statistics and Epidemiology Research Corporation: Washington.

13 World Health Organisation. Main findings of the comparative study of social and biological effects on perinatal mortality. WHO Q Rep 1978; 31: 74-83.

14 Forbes JF, Boddy FA, Pickering R, Wyllie MM. Perinatal mortality in Scotland 1970-79. J Epidemiol Community Health 1982; 36: 282-288.

15 Bulter NR, Alberman ED. The Second report of the 1958 British perinatal mortality survey. Livingstone: Edinburgh and London, 1969.

16 Jelliffe DB. The assessment of nutritional status of the community. WHO Monograph Series, No. 5. World Health Organization: Geneva, 1996.

17 Cnattingius S, Haglund B, Meirik O. Cigarette smoking as risk factor for late fetal and early neonatal death. Br Med J 1988; 297: $258-261$.

18 Schwartz D et al. Smoking and pregnancy: results of a prospective study of 6989 women. Eur J Clin Biol Res 1972; 17: 867-879.

19 Kaminski M, Rumeau C, Schwartz D. Alcohol Consumption in pregnant women and the outcome of pregnancy. Alcoholism (NY) 1978; 2: 155-163.

20 Little RE, Wendt JK. The effects of maternal drinking in the reproductive period: an epidemiologic review. J Subst Abuse Treatment 1991; 3: 187-204.

21 Naeye RL. Weight gain and the outcome of pregnancy $A m J$ Obstet Gynecol 1979; 135: 3-9. 